\title{
Effects of the snow cover on Antarctic sea ice and potential modulation of its response to climate change
}

\author{
Hajo Eicken, Holger Fischer and Peter Lemke \\ Alfred-Wegener-Institut für Polar- und Meeresforschung, Postfach 121061, D-27515 Bremerhaven, Germany
}

\begin{abstract}
Based on presented field data, it is shown that snow contributes roughly $8 \%$ to the total mass of ice in the Weddell Sea. Snow depth averages $0.16 \mathrm{~m}$ on first-year ice (average thickness $0.75 \mathrm{~m}$ ) and $0.53 \mathrm{~m}$ on second-year ice (average thickness $1.70 \mathrm{~m}$ ). Due to snow loading, sea ice is depressed below water level and flooded by sea water. As a result of flooding, snow ice forms through congelation of sea water and brine in a matrix of meteoric ice (i.e. snow). Sea-ice growth has been simulated with a one-dimensional model, treating the evolution of salinity, porosity and thermal properties of the ice. Simulations demonstrate that in the presence of a snow cover, ice growth is significantly reduced. Brine volumes increase by a factor of 1.5-2, affecting properties such as ice strength. Snow-ice formation depends on the evolution of freeboard and ice permeability. Effects of accumulation-rate changes have been assessed for the Weddell Sea with a large-scale sea-ice model accounting for snow-ice formation. Results for different scenarios are presented and compared with field data and one-dimensional simulations. The role of snow in modulating the response of Antarctic sea ice to climate change is discussed.
\end{abstract}

\section{INTRODUCTION}

The sea-ice zone is one of the most responsive components of the cryosphere with respect to global climate change. Given the projected amplification of a global temperature rise in the polar regions, the extent and thickness of the sea-ice cover in the Arctic and Antarctic may become major yardsticks in monitoring environmental change (Mitchell and others, 1990). Through the ice-albedo feedback and owing to its importance for ocean-atmosphere interaction, sea ice not only records but also drives climate variability. While it is well established that ice extent and ice-thickness distribution are key variables in this context, the role of snow in determining the growth and decay of a sea-ice cover has received much less attention.

In the Antarctic, where snow depths on sea ice may attain a third or a half of the ice thickness and where accumulation rates are highly variable in time and space, one would expect pronounced snow-cover effects. In this study we assess how and to what degree a snow cover affects seasonal and inter-annual variability in thickness, extent and properties of sea ice. First, data on the distribution of snow on sea ice in the Weddell Sea are presented and important processes in the interaction between snow and ice are identified. Based on these results, thermodynamic growth of an ice cover with different snow-accumulation rates is studied with the aid of a one-dimensional sea-ice model developed from the work of Maykut and Untersteiner (1971) and Cox and Weeks (1988). Finally, the large-scale pack-ice behaviour under the influence of varying snow-accumulation rates is assessed for the Weddell Sea with a dynamic thermodynamic mixed-layer sea-ice model (Fischer and Lemke, 1994). In a synthesis of these three lines of investigation, the quantitative impact of snow on the evolution of ice thickness, extent and properties will be deduced and its importance in modulating the response of sea ice to global climatic change will be evaluated.

\section{DEDUCING SNOW-COVER EFFECTS FROM FIELD MEASUREMENTS AND ICE-CORE STUDIES}

The distribution of snow on sea ice and its contribution to the total ice mass in the Weddell Sea have been derived from measurements and ice-core analysis carried out during a number of field studies on board the ice-breaker Polarstern. Here, data collected during the winter Weddell Gyre study (WWGS), traversing the entire Weddell Gyre in 1989 and 1992 (Fig. 1; for details on expeditions and sampling techniques, see Eicken and others, 1994), and the European Polarstern study (EPOS) in 1988 are presented. Table 1 shows mean values of snow depth $z_{\mathrm{s}}$, ice thickness $z_{\mathrm{i}}$ and freeboard $z_{\mathrm{fb}}$ determined through thickness drilling along profiles of $50-100 \mathrm{~m}$ length (1 or $2 \mathrm{~m}$ spacing) with over 5000 individual measurements. The results show that snow depth mostly amounts to roughly one-quarter of the ice thickness, with an extreme value of close to one-half for second-year ice sampled during WWGS 89.

The ice surviving summer in the perennially icecovered western branch of the Weddell Gyre (Fig. 1) and 


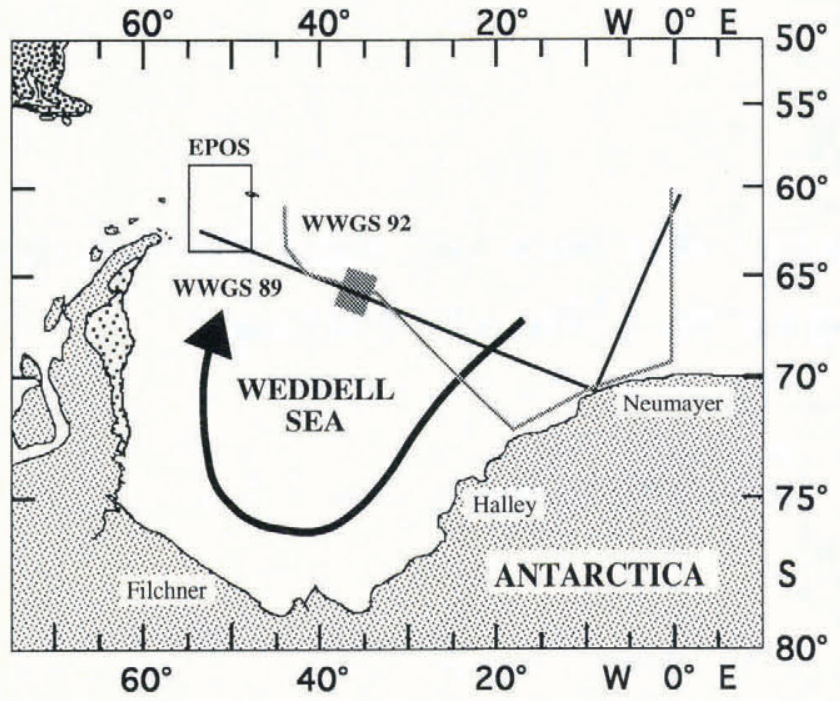

Fig. 1. Polarstern cruise tracks during WWGS in 1989 and 1992 and EPOS in 1988. The shaded box marks the approximate location of the boundary between predominantly second-year ice in the west and first-year ice in the east as determined during the WWGS cruises.

entering its second year of growth is characterized by a disproportionate increase in snow depth over ice thickness as compared to first-year ice. Apart from snow accumulating during summer, this is a result of the thermal insulation a snow cover provides. Since its thermal conductivity is an order of magnitude less than that of sea ice (for an average snow density of $290 \mathrm{~kg} \mathrm{~m}^{-3}$ measured during WWGS 89, its thermal conductivity amounts to roughly $0.2 \mathrm{~W} \mathrm{~m}^{-1} \mathrm{~K}^{-1}$ according to standard models, as compared to values at or above $2 \mathrm{~W} \mathrm{~m}^{-1} \mathrm{~K}^{-1}$ for sea ice), conductive heat flux and hence ice-growth rate are greatly reduced below a snow blanket. This is also seen in individual thickness-drilling profiles through level ice, where snow depth displays a strong negative correlation with ice thickness (Eicken and others, 1994).

Trapping of snow within pressure-ridge zones may increase snow depth by a factor of two to five over mean values in adjacent level areas. Areas where the snow cover exceeds a critical threshold or where deformation processes locally offset the isostatic balance such that the floe surface is depressed below sea level, are prone to flooding. Provided that hydraulic pathways such as cracks or extended vertical channels exist, sea water and brine seep into the snow cover and may eventually congeal into snow ice, consisting of a marine (mostly seawater) and a meteoric (snow) component. Field measurements show that negative freeboard as a prerequisite to snow-ice formation is exceedingly common in the Weddell Sea, with $z_{\mathrm{fb}}<0$ for $15 \%$, $40 \%$ and $8 \%$ of all EPOS, WWGS 89 and WWGS 92 measurements, respectively. Similar observations have been made in other sectors of the Antarctic, such as the Bellingshausen and Amundsen Seas (Jeffries and others, 1994).

The fraction of meteoric ice hidden in the solid ice cover can be retrieved from stable-isotope measurements of sea-ice cores (Lange and others, 1990; Eicken and others, 1994). The fraction of the heavy isotope ${ }^{18} \mathrm{O}$ in sea water greatly exceeds that in snow, since the light isotope is enriched in precipitation during evolution of the source vapour. Hence, the fraction of snow (i.e. meteoric ice) in a given sea-ice sample can be derived from the masscontinuity equations for salt and ${ }^{18} \mathrm{O}$ (for details, see Eicken and others, 1994). The contribution of meteoric ice to the total mass of ice and snow in the Weddell Sea deduced from WWGS 89 cores is shown in Table 2. Note in particular that the meteoric-ice fraction as well as the snow fraction is significantly larger for second-year than for first-year ice (this difference would increase when accounting for brine drainage from second-year ice, which results in an underestimate of the meteoric-ice fraction). Comparison with data from the winter Weddell Sea project 1986 indicates that the distribution of snow and meteoric ice varies both regionally and interannually (Eicken and others, 1994). This is in part explained by variable accumulation rates, but model results presented below indicate that the timing of the iceedge advance during autumn and winter also plays an important role, since snow accumulation only has an

Table 2. Fraction of snow $f_{\mathrm{s}}$ and meteoric ice $f_{\mathrm{m}}$ of the total thickness $z_{\mathrm{t}}$ of snow and ice in the Weddell Sea (WWGS 89, $n=21$ )

$\begin{array}{lll}z_{\mathrm{t}} & f_{\mathrm{s}} & f_{\mathrm{m}} \\ \mathrm{m} & \% & \%\end{array}$

\begin{tabular}{lrrr}
\hline First-year ice & 1.02 & 7 & 3 \\
Second-year ice & 2.47 & 11 & 5 \\
All & 1.23 & 8 & 4
\end{tabular}

Table 1. Mean values of snow depth $z_{\mathrm{s}}$, ice thickness $z_{\mathrm{i}}$ and freeboard $z_{\mathrm{fb}}$ for first-and second-year ice in the Weddell Sea

\begin{tabular}{|c|c|c|c|c|c|c|c|c|}
\hline \multirow[t]{3}{*}{ Expedition, date } & \multicolumn{4}{|c|}{ First-year ice } & \multicolumn{4}{|c|}{ Second-year ice } \\
\hline & $z_{\mathrm{s}}$ & $z_{\mathrm{i}}$ & $z_{\mathrm{fb}}$ & $n$ & $z_{\mathrm{s}}$ & $z_{\mathrm{i}}$ & $z_{\mathrm{fb}}$ & $n$ \\
\hline & $\mathrm{m}$ & $\mathrm{m}$ & $\mathrm{m}$ & & $\mathrm{m}$ & $\mathrm{m}$ & $\mathrm{m}$ & \\
\hline EPOS Oct./Nov. 1988 & 0.25 & 1.04 & 0.04 & 837 & 0.39 & 1.65 & 0.05 & 716 \\
\hline WWGS Sep./Oct. 1989 & 0.20 & 0.82 & 0.01 & 4229 & 0.70 & 1.77 & 0.06 & 631 \\
\hline WWGS June/Aug. 1992 & 0.07 & 0.70 & 0.04 & 222 & 0.28 & 1.21 & 0.06 & 94 \\
\hline
\end{tabular}


effect once a platform for deposition has been established. Given the complexity of the ocean-ice-atmosphere system and the comparatively small snow and sea-ice data base, the effects of changes in the boundary conditions driving growth and decay of ice are best assessed through numerical simulation, as attempted in the following sections.

\section{RESULTS FROM A ONE-DIMENSIONAL THERMODYNAMIC ICE-GROWTH/SALINITY MODEL}

Thermodynamic growth of an ice cover subjected to variable snow-accumulation rates and allowing for snowice formation has been numerically simulated, based on the one-dimensional model formulated by Maykut and Untersteiner (1971; abbreviated as M \& U). Despite ice thicknesses in the range of $0.5-1.5 \mathrm{~m}$ which would still justify the assumption of linear temperature profiles in the ice, the M \& U model, which allows for non-linear profiles by solution of the heat-conduction equation, is preferred in order to correctly capture thermal evolution of the ice under deeper snow cover and during snow-ice formation.

In short for a detailed description see $\mathrm{M} \& \mathrm{U}$; refer to Eicken (1992) for modifications made with respect to Weddell Sea climate), the surface temperature is derived in the model from the surface-energy balance given by

$$
(1-\alpha) F_{\mathrm{r}}-I_{0}+F_{\mathrm{l}}-F \uparrow+F_{\mathrm{s}}+F_{\mathrm{e}}+F_{\mathrm{c}}+F_{\mathrm{m}}=0
$$

with surface albedo $\alpha$, incoming long-wave and shortwave fluxes $F_{1}$ and $F_{\mathrm{r}}$ (of which $I_{0}$ enter the deeper ice layers; see M \& U for details), outgoing long-wave flux $F \uparrow$, sensible and latent heat fluxes $F_{\mathrm{s}}$ and $F_{\mathrm{e}}$, conductive flux $F_{\mathrm{c}}$, and heat loss due to melting of snow and ice $F_{\mathrm{m}}$. Heat conduction for a temperature distribution $T$ with depth $z$ is described by

$$
(\rho c)_{\mathrm{i}} \frac{\partial T_{\mathrm{i}}}{\partial t}=k_{\mathrm{i}} \frac{\partial^{2} T_{\mathrm{i}}}{\partial z^{2}}+\kappa_{\mathrm{i}} I_{0} \exp \left(-\kappa_{\mathrm{i}} z\right)
$$

with thermal conductivity $k$, density $\rho$ and specific heat $c$ here and below, the subscripts $\mathrm{i}$ and $\mathrm{s}$ denote variables referring to the ice and snow columns, respectively). The absorption of short-wave solar energy in the ice is also accounted for with an absorption coefficient $\kappa_{\mathrm{i}}$. Thermal conduction in the snow is described in analogue, ignoring short-wave absorption due to the strong attenuation in the upper snow layers. Snow thermal conductivity is taken as $0.23 \mathrm{~W} \mathrm{~m}^{-1} \mathrm{~K}^{-1}$ for a density of $290 \mathrm{~kg} \mathrm{~m}^{-3}$ according to the model of Anderson (1976). At the ice bottom (i.e. at depth $h_{\mathrm{s}}+h_{\mathrm{i}}$ ) heat conduction is balanced against oceanic heat flux $F_{\mathrm{w}}$ and release of latent heat of freezing $L$ :

$$
\kappa_{\mathrm{i}}\left(\frac{\partial T_{\mathrm{i}}}{\partial z}\right)_{h_{\mathrm{i}}+h_{\mathrm{i}}}-F_{\mathrm{w}}=\left[\rho L \frac{\mathrm{d}\left(h_{\mathrm{s}}+h_{\mathrm{i}}\right)}{\mathrm{d} t}\right]_{h_{\mathrm{s}}+h_{\mathrm{i}}} .
$$

In situ temperature $T_{\mathrm{i}}$ and salinity $S_{\mathrm{i}}$ control the volume of liquid brine within the ice, which in turn strongly influences thermal conductivity $k_{\mathrm{i}}$ and specific heat capacity $c_{\mathrm{i}}$. In our modified M \& $\mathrm{U}$ model, these terms are prognostic variables depending on $S_{\mathrm{i}}$ and $T_{\mathrm{i}}$ as formulated by Ono (1975) and M \& U. The salinity evolution of the ice is derived from a semi-empirical simulation scheme by Cox and Weeks (1988; abbreviated as $C \& W)$. In C \& W the initial salinity of a newly grown ice layer $S_{\mathrm{i} 0}$ is determined by a growth-rate-dependent effective-distribution coefficient $k_{\text {eff }}$ and the sea-water salinity $S_{\mathrm{w}}$ :

$$
S_{\mathrm{i} 0}=\kappa_{\mathrm{eff}} S_{\mathrm{w}} .
$$

Desalination of ice layers is accounted for as brine expulsion due to differential decrease in ice-brine volume $V_{\mathrm{b}}$ with cooling from $T_{1}$ to $T_{2}$ :

$$
\frac{V_{\mathrm{b}}\left(T_{2}\right)}{V_{\mathrm{b}}\left(T_{1}\right)}=\frac{S_{\mathrm{b}}\left(T_{1}\right)^{1 / \rho_{\mathrm{l}}}}{S_{\mathrm{b}}\left(T_{2}\right)} \exp \left(\frac{\mathrm{d} \rho_{\mathrm{b}}}{\mathrm{d} T} \frac{S_{\mathrm{b}}\left(T_{1}\right)-S_{\mathrm{b}}\left(T_{2}\right)}{\rho_{\mathrm{i}}}\right)
$$

where $S$ is salinity, and $\rho$ density of brine (subscript b) and ice. For $V_{\mathrm{b}} \geq 50 \%$, gravity drainage reduces ice salinity by replacement of cold, saline brine with salt solution of lesser density:

$$
\frac{\Delta S_{\mathrm{i}}}{\Delta t}=1.68 \times 10^{-5}\left(\frac{\Delta T}{\Delta z}\right)-3.37 \times 10^{-7} V_{\mathrm{b}}\left(\frac{\Delta T}{\Delta z}\right) \text {. }
$$

Details of the salinity model can be found in C \& W and Eicken (1992). To assess the evolution of snow-ice layers a simple flooding scheme has been incorporated into the model. The density $\rho(T, S)$ of the ice cover is computed from $C$ \& W and ice freeboard determined according to

$$
z_{\mathrm{fb}}=z_{\mathrm{i}}-\left(\frac{\rho_{\mathrm{i}} z_{\mathrm{i}}+\rho_{\mathrm{s}} z_{\mathrm{s}}}{\rho_{\mathrm{w}}}\right)
$$

with $z$ as thickness of ice and snow cover, and $\rho$ as density of ice, snow and sea water (subscript w).

When flooding the snow cover up to a height of $-z_{\mathrm{fb}}$ for $z_{\mathrm{fb}}<0$, the boundary conditions of the model are modified such that (1) the temperature of the infiltrating water and the snow matrix is set to the freezing point of sea water, (2) the density of the infiltrated snow layer is increased by a factor of 1.5 due to settling of the snow grains (in accordance with field observations on wet and flooded snow), (3) the thickness of the overlying snow column is reduced correspondingly, and (4) until complete freezing of the flooded layer, which thermally decouples the ice bottom from the surface, no net accretion/ablation is allowed at the ice bottom. While natural conditions are not fully represented in such a simplified scheme, the results presented below demonstrate that the conclusions about the importance of snowice formation are nevertheless valid. The model has been programmed on a microcomputer; the heat conduction equations have been solved with an explicit finitedifference scheme for layer thicknesses of $0.01 \mathrm{~m}$ (snow) and $0.02 \mathrm{~m}$ (ice).

Computation of the salinity evolution is nested between time steps of $290 \mathrm{~s}$ for heat conduction. The model is driven by climatological data from the central and eastern Weddell Sea (see Eicken (1992) for details). Apart from model validation carried out by C \& W and Eicken (1992), simulated thicknesses have been compared 
with data and model results from Neumayer Station in the Antarctic (Kipfstuhl, 1991).

Results from standard model runs for different accumulation rates, not accounting for snow-ice formation, are shown in Figure 2. In accordance with the iceedge advance in the Weddell Sea (as seen in the satellite data of Gloersen and others (1992) and in Figure 5 below for the large-scale model) ice growth is initiated on 1 May (Julian day 121). Shortly after melting sets in, simulations are terminated because, at present, salt fluxes in melting ice are inadequately represented. The oceanic heat flux $F_{\mathrm{w}}$ is set to $4 \mathrm{~W} \mathrm{~m}^{-2}$ to match results of the large-scale model (see below). Accumulation rates are given as water equivalent such that they have to be divided by the snow

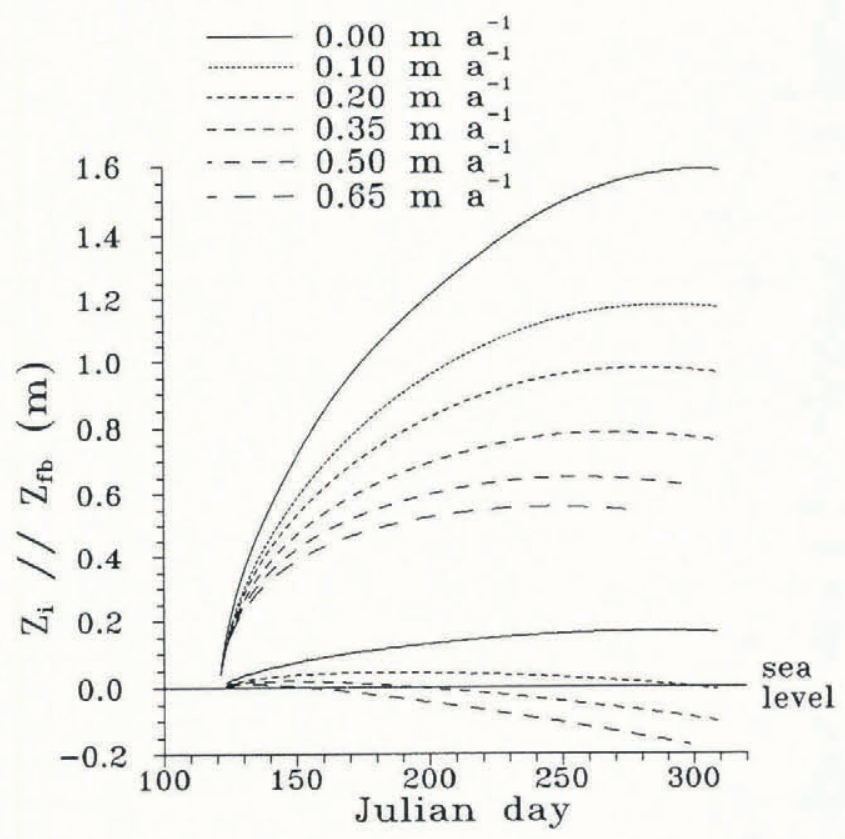

Fig. 2. Evolution of ice thickness $z_{\mathrm{i}}$ from simulations with varying accumulation rates (w.e.), without snow-ice formation. Starting date of ice formation 1 May; oceanic heal flux $F_{\mathrm{w}}=4 \mathrm{~W} \mathrm{~m}^{-2}$. Nole how maximum ice thickness is altained earlier for increasing accumulation rates. The lower set of curves shows time series of freeboard $z_{\mathrm{fb}}$ relative to sea level, with negative freeboard for accumulation rates 0.35 and $0.5 \mathrm{ma}^{-1}$, potentially inducing flooding and snow-ice formation during the latter half of the growth season. density to yield snow-accumulation rates. In the model, snow depth increases linearly with every time step. Based on accumulation data from overwintering stations and glacial-ice cores from the Weddell Sea region, the best estimate for accumulation rates ranges between 0.2 and $0.35 \mathrm{ma}^{-1}$ (Eicken and others, 1994). Snow depths measured on sea ice point towards a best estimate of $0.2 \mathrm{~m} \mathrm{a}^{-1}$ (i.e. snow depth of $0.34 \mathrm{~m}$ on Julian day $300 \mathrm{in}$ Figure 2). Field data as listed in Table 1 range below this number, mostly because (1) field measurements were carried out before day 300 and include ice formed after day 121 , (2) snow is removed by wind action, and (3) snow-ice formation decreases snow depth Eicken and others, 1994).

The results shown in Figure 2 and all other runs with different boundary conditions (date of ice formation 15 March-1 August; $0 \leq F_{\mathrm{w}} 20 \leq \mathrm{W} \mathrm{m}^{-2}$ ) indicate that the net effect of increasing snow-accumulation rates $\mathrm{d} z_{\mathrm{s}} / \mathrm{d} t$ on sea ice is a pronounced decrease in maximum thickness $z_{\text {i,max }}$ attained through thermodynamic growth. Furthermore, the higher $\mathrm{d} z_{\mathrm{s}} / \mathrm{d} t$, the earlier $z_{\mathrm{i}, \max }$ is attained and melting sets in (Fig. 2; Table 3). As compared to the zeroaccumulation run $\left(z_{\mathrm{i}, \max }=1.59 \mathrm{~m}\right.$ on day 290$), z_{\mathrm{i}, \max }$ is reduced by a factor of $0.6\left(z_{\mathrm{i}, \max }=0.98 \mathrm{~m}\right.$ on day 278$)$ and $0.4\left(z_{i, \max }=0.65 \mathrm{~m}\right.$ on day 251$)$ for accumulation values of 0.2 and $0.5 \mathrm{ma}^{-1}$, respectively. In the simulations, snow also enhances the sensitivity of the ice cover to oceanic heat flux $F_{\mathrm{w}}$. As compared to an accumulation of $0.2 \mathrm{~m} \mathrm{a}^{-1}$ with $F_{\mathrm{w}}=4 \mathrm{~W} \mathrm{~m}^{-2}$, an increase in $F_{\mathrm{w}}$ to $10 \mathrm{~W} \mathrm{~m}^{-2}$ results in a decrease of $z_{\mathrm{i}, \max }$ by a factor of 0.8. Attainment of $z_{\mathrm{i}, \max }$ sets in $38 \mathrm{~d}$ earlier.

Accumulation of snow on the ice surface affects not only the thickness of the ice cover but also its properties, namely salinity and brine volume. The upper layers in bare sea ice cool down to values approaching the air temperature; consequently brine volumes are comparatively low (Fig. 3). Thermal insulation by a snow cover causes ice temperatures to increase which in turn results in brine volumes exceeding $80 \%$ in the upper layers for accumulation rates above $0.35 \mathrm{~m} \mathrm{a}^{-1}$ (Fig. 3). By damping ice-growth rates, a snow cover also diminishes initial salinities of newly accreted layers, yet, as Figure 3 demonstrates, this cannot compensate for the temperature effect (see also Eicken, 1992). With increasing snowaccumulation rates, ice strength, which scales with ice thickness and inversely with brine volume (Mellor, 1986), is greatly reduced. As discussed below, such a "softening",

Table 3. Maximum annual thickness $z_{\mathrm{i}, \max }$ or volume $V_{\mathrm{i}, \max }$ of sea ice and day of atlainment $d_{\max }$ for different accumulation rates (w.e.) from one-dimensional thermodynamic and large-scale sea-ice models

\begin{tabular}{|c|c|c|c|c|}
\hline \multirow{2}{*}{$\begin{array}{l}\text { Accumulation rate } \\
\qquad \mathrm{m} \mathrm{a}^{-1} \text { w.e. }\end{array}$} & \multicolumn{2}{|c|}{ One-dimensional thermodynamic model } & \multicolumn{2}{|c|}{ Large-scale model } \\
\hline & $\begin{array}{c}z_{\mathrm{i}, \max } \\
\mathrm{m}\end{array}$ & $d_{\max }$ & $\begin{array}{c}V_{\mathrm{i}, \max } \\
\mathrm{km}^{3}\end{array}$ & $d_{\max }$ \\
\hline 0.00 & 1.59 & 299 & $15.2 \times 10^{3}$ & 282 \\
\hline 0.10 & 1.18 & 287 & $13.9 \times 10^{3}$ & 282 \\
\hline 0.20 & 0.98 & 278 & $12.9 \times 10^{3}$ & 282 \\
\hline 0.35 & 0.79 & 263 & $12.0 \times 10^{3}$ & 282 \\
\hline 0.50 & 0.65 & 251 & $12.0 \times 10^{3}$ & 282 \\
\hline
\end{tabular}




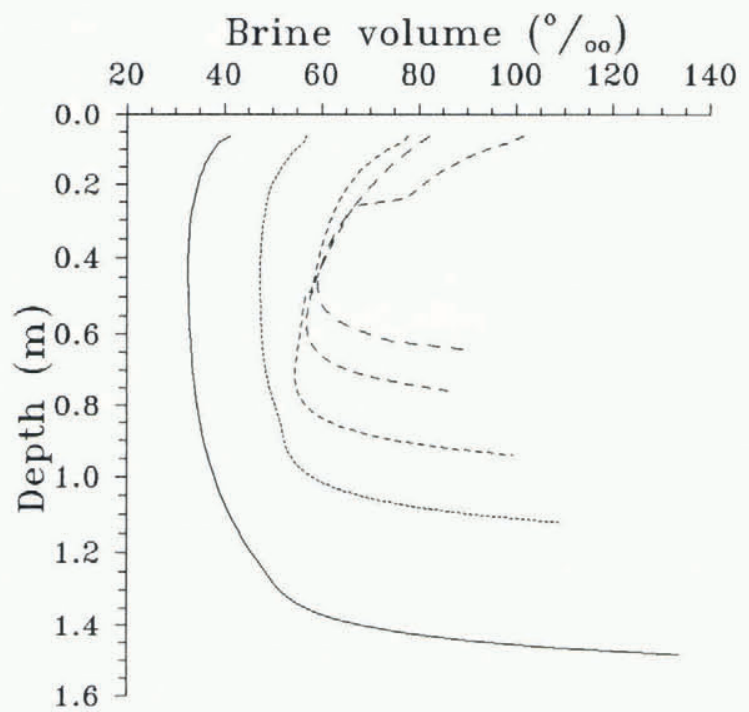

Fig. 3. Profiles of fractional brine volume for simulations shown in Figure 2 on Julian day 250, i.e. close to allainment of maximum ice thickness (for legend, see Fig. $2)$. Note the increase in brine volume for increasing snowaccumulation rates due to higher temperatures in the upper ice layers.

effect has significant implications for the large-scale behaviour of the ice pack.

The potential for flooding of the ice surface and the formation of snow ice is expressed in the time-series plot of freeboard $z_{\mathrm{fb}}$ in Figure 2. On day 300, $z_{\mathrm{fb}}=0.17,0.00$, -0.09 and $-0.17 \mathrm{~m}$ for accumulation rates of $0,0.2,0.35$ and $0.5 \mathrm{~m} \mathrm{a}^{-1}$, respectively. Thus, for the boundary conditions of the simulation, no snow ice forms for accumulation rates $\leq 0.2 \mathrm{ma}^{-1}$, and no substantial negative freeboard is reached for higher values of $\mathrm{d} z_{\mathrm{s}} / \mathrm{d} t$ before day 250. A further prerequisite for flooding to occur is the presence of a hydraulic pathway (e.g. cracks) between the ocean and the depressed ice surface. Flooding over wider areas of level ice is achieved only if the ice cover is sufficiently permeable to allow sea water to enter from below. Laboratory studies (see C \& W) and field experiments (unpublished information from Eicken and Haas, 1992) indicate that sea ice is effectively impermeable for brine volumes below 50-70\%. Hence, a lowporosity layer within an ice floe may prevent flooding despite negative freeboard. An indication that this permeability criterion may be of importance and requires further attention is given in Figure 4, which shows that the critical threshold of $50 \%$ is surpassed after day 230-250 for the most realistic accumulation rates. Generally, it appears that mid-winter ice temperatures are too low, even with higher snow loads, to allow flooding (excluding thin new ice). This is corroborated by field observations from WWGS 89 and 92 where surface flooding before day 250-270 was much less common, despite wide occurrence of negative freeboard, than during EPOS after day 290. The evidence that ice permeability is indeed a limiting factor in snow-ice formation implies that the complexity of an ice cover's response to different snow-accumulation rates is greater than suggested by a simple flooding criterion as derived in Equation (7).

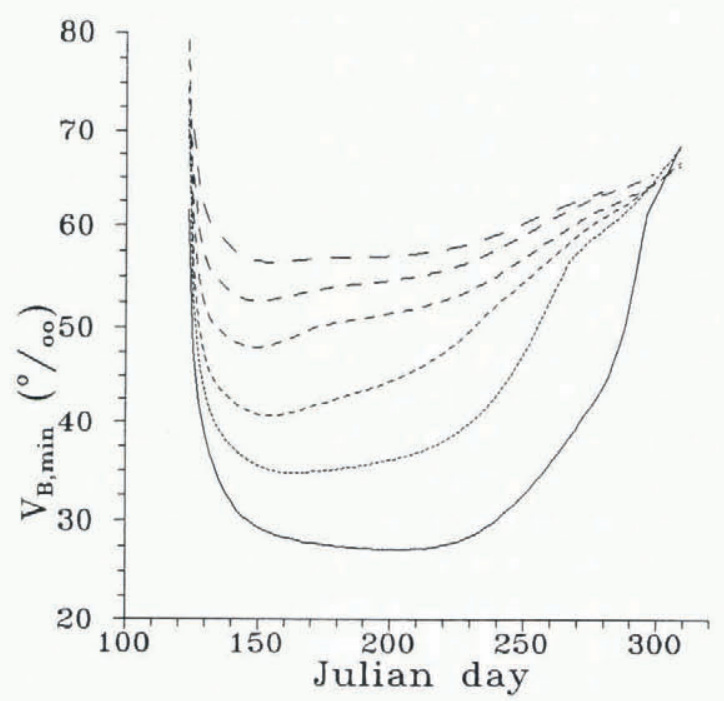

Fig. 4. Time series of minimum brine volume $V_{\mathrm{b}, \min }$ in ice-growth simulations shown in Figure 2 (for legend, see Fig. 2). Note how critical permeability threshold of $V_{\mathrm{b}, \min }>50-70 \%$ is surpassed only during the later part of the growth season.

The evolution of the freeboard layer determines the sustainable growth of snow ice (Fig. 2; bottom). For an accumulation rate of $0.5 \mathrm{~m} \mathrm{a}^{-1}$, for example, $z_{\mathrm{fb}}$ amounts to $-0.10 \mathrm{~m}$, i.e. $15 \%$ of $z_{\mathrm{i}, \max }$ on day 250 . Results from the ice-growth/salinity model indicate, however, that snowice congelation is limited to smaller amounts due to energetic constraints. The dividing line between complete and incomplete congelation of a flooded snow layer is evident from the data shown in Table 4. For accumulation rates $\geq 0.5 \mathrm{~m} \mathrm{a}^{-1}$, only part of the flooded freeboard layer congeals, if flooding takes place after day 230 . Flooding after day 250 results in incomplete congelation for all simulated accumulation rates. Only for ice growth starting very early in the season or for high oceanic heat fluxes is the ice surface depressed farther below sea level with $z_{\mathrm{fb}}$ ranging between -0.1 and $-0.3 \mathrm{~m}$ (see Table 4 ). While a detailed assessment of snow-ice formation requires additional data on the prerequisites and the salt flux associated with flooding and snow-ice formation,

Table 4. Freeboard $z_{\mathrm{fb}}$ before flooding and thickness of congealed snow ice $z_{\mathrm{si}}$ for different accumulation rates (w.e.) and dates of ice formation $d_{\mathrm{i}, \mathrm{s}}$ and start of snow-ice congelation $d_{\text {si.s }}$

\begin{tabular}{ccccc}
\hline $\begin{array}{c}\text { Accumulation rate } \\
\mathrm{m} \mathrm{a}^{-1}\end{array}$ & $d_{\mathrm{i}, \mathrm{s}}$ & $d_{\mathrm{si}, \mathrm{s}}$ & $\begin{array}{c}z_{\mathrm{fb}} \\
\mathrm{m}\end{array}$ & $\begin{array}{c}z_{\mathrm{si}} \\
\mathrm{m}\end{array}$ \\
\hline 0.50 & 121 & 230 & -0.07 & 0.07 \\
0.50 & 121 & 250 & -0.10 & 0.05 \\
0.35 & 121 & 250 & -0.04 & 0.04 \\
0.35 & 76 & 220 & -0.08 & 0.08 \\
0.35 & 76 & 250 & -0.10 & 0.04 \\
0.20 & 76 & 250 & 0.01 & 0.01 \\
\hline
\end{tabular}


it appears that the amount of snow ice formed due to flooding under a snow load cannot nearly compensate the decrease in ice thickness due to enhanced thermal insulation (Fig. 2; Tables 3 and 4). At best, snow-ice formation counterbalances decreases in $z_{i, \max }$ for $0.1 \mathrm{~m} \mathrm{a}^{-1}$ accumulation-rate increments.

The role of snow in modulating the response of sea ice to climate change extends through to the period of summer melt. To date, ablation processes in Antarctic sea ice are not well enough understood to extend the onedimensional model far into the melt season. Field data indicate that the situation is different from the Arctic Ocean, where the entire snow cover melts away at the surface of multi-year ice. Nevertheless, an important result of the work of Maykut and Untersteiner (1971) also applies to the Southern Ocean. They found that an increase in accumulation on multi-year ice beyond approximately $0.6 \mathrm{~m} \mathrm{a}^{-1}$ of snow induced an increase in equilibrium ice thickness (i.e. steady state achieved for a balance between surface summer melt and bottom freezing in winter). Thus, a thick snow cover persisting year-round protects the underlying ice from downwarddirected heat fluxes and increases its chance of surviving summer melt. Even though Antarctic climate differs from that of the Arctic, there is evidence that such "snow shielding" occurs in some perennially ice-covered areas, such as the western Weddell Sea (Table 1), today. In the Bellingshausen and Amundsen Seas, where accumulation rates exceed those of the Weddell region by more than a factor of two (Eicken and others, 1994, Jeffries and others, 1994), snow may also prevent complete melting of the ice cover during summer.

\section{RESULTS FROM A LARGE-SCALE SEA-ICE MODEL}

The large-scale dynamic-thermodynamic sea-ice model, based on work by Hibler (1979), is coupled to a onedimensional oceanic mixed-layer model which determines the oceanic heat flux prognostically (Lemke and others, 1990). Similar to Owens and Lemke (1990), a snow layer is included in the model. Through continuity equations, ice thickness, ice compactness and snow depth are prognostically calculated variables, composed of thermodynamic and dynamic terms. From the momentum equation, an ice velocity is determined, allowing for spatial and temporal variability of ice thickness, ice compactness and snow depth through advection and diffusion. Additionally, internal ice stresses are considered, based on a viscous-plastic ice rheology (Hibler, 1979 ).

The heat-budget calculations are based on formulations of Parkinson and Washington (1979). A linear temperature profile is assumed in the snow and ice layers according to Semtner (1976). A scheme for snow/ice conversion, which considers flooding of ice floes due to snow loading (Leppäranta, 1983), is added to the thermodynamic part of the model. The large-scale model domain represents the South Atlantic region from $60^{\circ} \mathrm{W}$ to $60^{\circ} \mathrm{E}$ and from $80^{\circ}$ to $47.5^{\circ} \mathrm{S}$. A polar stereographic grid is used with a spatial resolution of $2.5^{\circ} \times 2.5^{\circ}$. The model is integrated in daily time steps to obtain updates of sea-ice conditions. After 6 years of integration with the 1986 atmospheric forcing, the model reached an equilibrium seasonal cycle with respect to ice volume. Using the ice conditions of the last day in 1986, a transient run for 1987 is started and used in these analyses. The daily forcing data originate from the European Centre for Medium Range Weather Forecasts (ECMWF) and include the wind components, air temperature, relative humidity and air pressure for 1986 and 1987. The forcing terms are the same as those used by Fischer and Lemke (1994).

Model results of ice volume for a complete annual cycle are shown in Figure 5 for different accumulation rates. Maximum ice volumes are in all cases attained around Julian day 282 (9 October). Compared to the one-dimensional model (Fig. 2; Table 3), ice volume does not decrease as drastically with increasing accumulation rates, and is reduced at most by $21 \%$ when comparing 0 and $0.35 \mathrm{~m} \mathrm{a}^{-1}$ accumulation scenarios. This reduction of the insulation effect is due to the fact that new ice growth along the advancing ice edge contributes significantly to the rise in ice volume during the growth season. On young ice, snow-cover effects do not play as important a role as in a one-dimensional scenario, where only one icethickness class is monitored. Analysis of model runs furthermore indicates that neither oceanic heat flux nor the amount of ice deformation are significantly affected by varying accumulation rates.

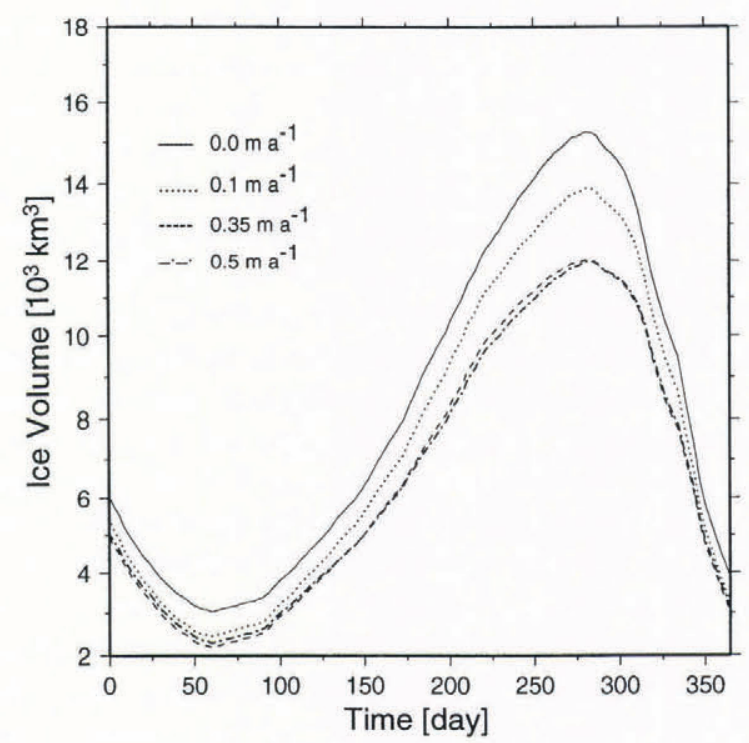

Fig. 5. Time series of total sea-ice volume in the Weddell Sea for different accumulation rates (w.e.) as computed with the large-scale sea-ice model.

For accumulation rates of 0.35 and $0.5 \mathrm{~m} \mathrm{a}^{-1}$ differences in ice volume are negligible, while accumulation rates $>0.5 \mathrm{~m} \mathrm{a}^{-1}$ induce an increase in ice volume due to the growing contribution of snow ice. This is demonstrated in Figure 6, with negligible snow-ice formation for rates $\leq 0.2 \mathrm{~m} \mathrm{a}^{-1}$ and a distinct increase for values $\geq 0.5 \mathrm{~m} \mathrm{a}^{-1}$. In the latter case, meteoric ice accounts for more than $10 \%$ of the total ice volume, an estimate which may have to be revised when taking into account the 


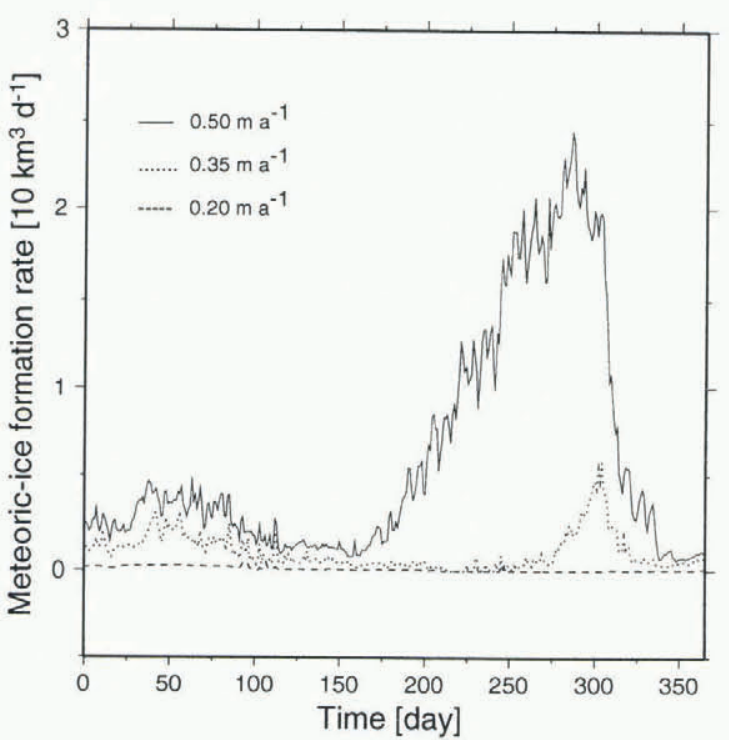

Fig. 6. Formation rates of meteoric ice from computations with the large-scale sea-ice model. Note how formation rates increase towards the end of the ice-growth season.

thermodynamic constraints and the prerequisites for flooding discussed above. Besides the correspondence with respect to a critical accumulation threshold slightly below $0.35 \mathrm{~m} \mathrm{a}^{-1}$, the temporal evolution of meteoric-ice formation rates compares well with the results from the one-dimensional model. Both indicate that the period between Julian days 220 and 280, i.e. the latter part of the ice-growth season, is critical for flooding and congelation which is partly explained by the freeboard evolution (Fig. 2 ). The large-scale model is furthermore able to reproduce the regional distribution pattern of snow and meteoric ice with a distinct maximum in the western Weddell Sea with prevailing second-year ice. In contrast with the ice-volume curves shown in Figure 5, the ice extent does not vary notably between simulations, i.e. with accumulation rates ranging between 0.0 and $0.65 \mathrm{~m} \mathrm{a}^{-1}$.

\section{DISGUSSION AND CONGLUSIONS}

In discussing the effects of snow on the Antarctic sea-ice cover, a distinction has to be made between local, "point" effects and the response of the entire Weddell Sea pack. The former have been studied in field measurements and a one-dimensional sea-ice growth model, indicating that increasing snow accumulation results in a net thinning of the ice cover due to enhanced thermal insulation from the atmosphere. The reduction in short-wave fluxes due to higher surface albedo does not come into play, with fluxes being low during most of the ice-growth season. Rising ice temperatures that accompany increases in snow depth have important consequences for ice properties. Simulations of the salt and temperature distribution within the ice indicate that fractional brine volumes rise drastically as accumulation rates increase from 0 to $0.5 \mathrm{ma}^{-1}$ or more. In combination with the decrease in ice thickness, this implies that regions of high snow accumulation develop an ice cover of significantly reduced strength. It still needs to be established, however, how such decrease in macroscopic ice strength affects large-scale ice deformation. Given the prevalence of dynamic icegrowth processes in the Antarctic, enhanced dynamic thickening may well counterbalance some of the thermodynamically induced thinning.

As brought out by the field data and confirmed by both models, snow contributes directly to sea-ice mass through congelation of snow ice. The one-dimensional model demonstrates, however, that flooding and snow-ice formation are critically affected by several intertwining processes. Among other factors, the timing of snow accumulation, the permeability of the underlying ice and the heat flux sustained at the surface combine to induce a highly non-linear response of the ice cover to changes in boundary conditions. This is confirmed by comparing meteoric-ice and freeboard data collected in different years from different sectors of the Weddell Sea Eicken and others, 1994). Both models indicate that snow-ice formation may buffer some of the reduction in ice thickness with increasing accumulation rates; it does not suffice however, to increase ice volumes to values achieved for ice with thin or no snow cover.

How does the snow cover modulate the response of Antarctic sea ice to climate change, such as a projected atmospheric warming due to anthropogenic greenhouse gas emissions? While it is not quite clear how accumulation rates in the Antarctic sea-ice zone will respond to a doubling of carbon-dioxide atmospheric concentrations (Mitchell and others, 1990), GCM simulations by Budd and Simmonds (1991) derived an increase in net accumulation (precipitation minus evaporation) ranging between $10 \%$ and $40 \%$. According to the large-scale sea-ice model, such changes would diminish ice volume only by smaller amounts with no alteration in ice extent. Precipitation and accumulation of snow are far from being spatially and temporally homogeneous processes as assumed in the model, however, and hence local effects can be much more pronounced. An increase in accumulation early in the season or near the advancing ice-edge zone would decrease ice-growth rates and result in enhanced snow-ice formation due to snow loading on comparatively thin ice (Fig. 2; Table 4; see also Eicken and others, 1994).

More importantly, the decrease in conductive heat flux $F_{\mathrm{c}}$ under a thicker snow cover enhances the sensitivity of thermodynamic ice growth to oceanic heat flux $F_{\mathrm{W}}$ as discussed above (see Equation (3)). At present the thickness of the Weddell Sea ice cover is closely checked by the balance between $F_{\mathrm{c}}$ and $F_{\mathrm{w}}$ (Gordon and Huber, 1990), which may imply that events driven by changes of $\left(F_{\mathrm{c}}-F_{\mathrm{w}}\right)$, such as a Weddell polynya, are likely to occur more frequently for increasing snow accumulation in the area.

While the snow cover enhances "bottom" sensitivity of sea ice, "top" sensitivity is decreased at the same time. First, snow acts as a buffer during the melting season, since the albedo does not decrease as drastically while meltwater may percolate downward within the snow column. As long as the ice surface remains unexposed and no melt puddles form, surface ablation progresses comparatively slowly. The perennial persistence of sea ice in regions of thicker snow cover, such as the western 
Weddell and the Bellingshausen Sea (Eicken and others, 1994; Jeffries and others, 1994) may be due to this "snowshielding" effect. In the Arctic, where oceanic heat fluxes are smaller, an increase in annual accumulation beyond $1.2 \mathrm{ma}^{-1}$ of snow induces an increase of equilibrium ice thickness to values exceeding $6 \mathrm{~m}$ (Maykut and Untersteiner, 1971). Clearly, these processes require further study, in particular since they may also buffer increasing summer air temperatures due to atmospheric warming.

A second important process in this context is snow-ice formation after flooding of the ice surface. The models employed in this study indicate that the process of snowice formation itself is correctly captured, yet that more detailed studies of the prerequisites and boundary conditions of flooding and congelation of snow ice are required. Models and field data indicate that, at present, meteoric ice represents a comparatively small, though significant, term in the sea-ice mass balance. For larger accumulation rates this contribution is likely to increase (Figs 5 and 6 ). With a best estimate of present-day accumulation rates between 0.2 and $0.35 \mathrm{ma}^{-1}$, the Antarctic regime may well be on the brink of enhanced snow-ice formation. Field results demonstrate that in exceptional locations or years, snow in the form of meteoric ice) contributes more than $25 \%$ to the total mass of sea ice even now (Eicken and others, 1994). The consequences are far from evident at present, yet they are potentially of great importance for an assessment of seaice response to enhanced accumulation rates. Thus, it could be argued that in regions where circulation patterns allow multi-year ice to develop, such a perennial ice cover would be stabilised through snow accumulation (even for rates $>1 \mathrm{ma}^{-1}$ w.e.). Snow-ice formation takes place in the freeboard layer, where maximum conductive heat fluxes are sustained and congelation is decoupled from the ocean by the underlying ice. As long as the ice surface is not exposed during summer melting, a stationary state comparable to Arctic multi-year cycling (Maykut and Untersteiner, 1971), yet mostly or entirely driven by snow-ice congelation, could be attained.

Issues requiring further attention are indicated by the shortcomings of this study. First, the snow cover is represented in a simplistic fashion in the simulations. While this suffices for an assessment of general patterns in snow-ice interaction, further studies would probably require a more sophisticated snow model, such as the one developed by Loth and others (1993). Similarly, snow-ice formation in the large-scale model may have to be revised to take into account energetic constraints (i.e. strict conservation of both mass and energy) for the congelation of a flooded snow layer. Most important of all, the "snow-shielding effect" needs to be studied in more detail both in the field and through numerical modelling, as it may be the most important mechanism in modulating the response of an ice cover to enhanced atmospheric warming during the melting season.

\section{REFERENCES}

Anderson, E. A. 1976. A point energy and mass balance model of a snow cover. NOAA Tech. Rep. NWS-19.

Budd, W. F. and I. Simmonds. 1991. The impact of global warming on the Antarctic mass balance and global sea level. In Weller, G., C. L. Wilson and B. A. B. Severin eds. International Conference on the Role of the Polar Regions in Global Change: proceedings... June 11-15, 1990 at the University of Alaska, Fairbanks. Vol. 2. Fairbanks, AK, University of Alaska, $489-494$.

Cox, G. F. N. and W.F. Weeks. 1988. Numerical simulations of the profile properties of undeformed first-year sea ice during the growth season. J. Geophys. Res., 93 (C10), 12,449-12,460.

Eicken, H. 1992. Salinity profiles of Antarctic sea ice: field data and model results. 7. Geophys. Res., $97(\mathrm{C10}), 15,545-15,557$.

Eicken, H., M. A. Lange, H. -W. Hubberten and P. Wadhams. 1994. Characteristics and distribution patterns of snow and meteoric ice in the Weddell Sea and their contribution to the mass balance of sea ice. Annales Geophysicae, 12 (1), 80-93.

Fischer, H. and P. Lemke. 1994. On the required accuracy of atmospheric forcing fields for driving dynamic - thermodynamic sea ice models. In Johannessen, O. M., R. D. Muench and J. E. Overland, eds., The polar oceans and their role in shaping the global emvironment. Washington, DC, American Geophysical Union, 373381. Geophysical Monograph, 85)

Gloersen, P., W.J. Campbell, D.J. Cavalieri, J. C. Comiso, C. L. Parkinson and H.J. Zwally. 1992. Arctic and Antarctic sea ice, 1978 1987: satellite passive-microwave observations and analysis. Washington, DC, National Aeronautics and Space Administration. (NASA SP-511.)

Gordon, A. L. and B. A. Huber. 1990. Southern Ocean winter mixed layer. 7. Geophys. Res., 95 (C7), 11,655-11,672.

Hibler, W. D., III. 1979. A dynamic thermodynamic sea ice model. $f$. Phys. Oceanogr., 9 (4), 815846.

Jeffries, M. O., R. A. Shaw, K. Morris, A. L. Veazey and H. R. Krousc, 1994. Crystal structure, stable isotopes $\left(\delta^{18} \mathrm{O}\right)$, and development of sea ice in the Ross, Amundsen, and Bellingshausen seas, Antarctica. 7. Geophys, Res., 99 (C1), 985-995.

Kipfstuhl, J. 1991. Zur Entstehung von Unterwassereis und das Wachstum und die Energiebilanz des Meereises in der Atka Bucht, Antarktis. Ber. Polarforsch. 85.

Lange, M.A., P. Schlosser, S.F. Ackley, P. Wadhams and G.S. Dieckmann. 1990 ${ }^{18} \mathrm{O}$ concentrations in sea ice of the Weddell Sea, Antarctica. J. Glaciol., 36(124), 315-323.

Lemke, P., W. B. Owens and W. D. Hibler, III. 1990. A coupled sea ice mixed layer-pycnocline model for the Weddell Sea. J. Geophys. Res., 95 C6), 95139525.

Leppäranta, M. 1983. A growth model for black ice, snow ice and snow thickness in subarctic basins. Nord. Hydrol., 14(2), $59-70$.

Loth, B., H. -F. Graf and J. M. Oberhuber. 1993. Snow cover model for global climatic simulations. J. Geophys. Res., 98 (D6), 10,451-10,464.

Maykut, G. A. and N. Untersteiner. 1971. Some results from a timedependent thermodynamic model of sea ice. 7. Geophys. Res., 76 6), $1550-1575$.

Mellor, M. 1986. Mechanical behavior of sea ice. In Untersteiner, N., ed. The geophysics of sea ice. New York, Plenum Press, 165-281. (NATO ASI Series. Ser. B. Physics, Vol. 146.

Mitchell, J.F.B., S. Manabe, V. Meleshko, and T. Tokioka. 1990. Equilibrium climate change - and its implications for the future. In Houghton, J. T., G.J. Jenkins, J.J. Ephraums, eds. Climate changethe IPCC scientific assessment. Cambridge, Cambridge University Press, $131-172$.

Ono, N. 1975. Thermal properties of sea ice. IV. CRREL Draft Translation 467.

Owens, W. B. and P. Lemke. 1990. Sensitivity studies with a sea ice mixed layer-pycnocline model in the Weddell Sea. J. Geophys. Res., 95 C6), 9527-9538.

Parkinson, C. L. and W.M. Washington. 1979. A large-scale numerical model of sea ice. J. Geophys. Res., 84 (C1), 311-337.

Semtner, A.J., Jr. 1976. A model for the thermodynamic growth of sea ice in numerical imvestigations of climate. J. Phys. Oceanogr., 6, 379 389. 